\title{
The relationship between motor skills, psychosocial adjustment and peer victimization in school-aged children
}

\section{Thorpe, L. Tremblay, C. Larivière, B. Chebbi}

Moriah Thorpe, MHK

Student, School of Human Kinetics

Laurentian University

ms_thorpe@laurentian.ca

Line Tremblay, PhD., C.Psych.

Associate Dean, Faculty of Health

Laurentian University

ltremblay@laurentian.ca

Céline Larivière, PhD., R. Kin.

Acting Dean, Faculty of Health

Laurentian University

clariviere@laurentian.ca

Brahim Chebbi, PhD., Eng.

Full Professor, Bharti School of Engineering

Laurentian University

bchebbi@laurentian.ca 


\begin{abstract}
The aim of this study was to investigate the relationships between children's motor competence, psychosocial adjustment, peer victimization, physical activity participation and obesity. Using the Elaborated Environmental Stress Hypothesis as the framework, we hypothesized that multiple stressors influence children with poor motor competence and that the pathway from motor competence to psychosocial maladjustment is more complex than initially thought. A sample of child-parent dyads $(\mathrm{n}=51$; children ages 7 to 10 years), were recruited from two educational institutions in Sudbury, Ontario. Child participants completed self-report measures on peer victimization, depression symptoms, loneliness and anxiety symptoms across five dimensions (social phobia, obsessive-compulsive disorder, separation anxiety, panic disorder and generalized anxiety). Child participants also completed the Test of Gross Motor Development3. Parent participants completed a sociodemographic questionnaire and a questionnaire on their child's levels of participation in physical activity. For boys, Pearson product-moment correlations revealed that lower motor competence was significantly related to depressive symptoms, social phobia, separation anxiety symptoms, loneliness and peer victimization. For girls, lower motor competence was significantly related to separation anxiety symptoms and loneliness. No correlations were found between motor competence, weight status and physical activity participation. Findings are consistent with previous literature. These findings suggest that (1) boys are more psychosocially affected and victimized than girls when measured against motor competence and, (2) children are experiencing these issues as early as age 7, which is a time when children are starting to build social relationships. More research is required strengthen these findings.
\end{abstract}

Key words: Gross motor skills, Motor development, Psychosocial maladjustment, Internalizing problems, Anxiety, Depression, Loneliness, Peer victimization, Bullying, Test of Gross Motor Development-3 


\section{Résumé}

Sur la base de l'hypothèse élargie du stress environnemental, l'objectif de cette étude était d'investiguer les relations entre la compétence motrice des enfants, l'adaptation psychosociale, la victimisation par les pairs, la participation à l'activité physique et l'obésité. Nous avons recruté un échantillon de 51 dyades parents-enfants âgées de 7 à 10 ans dans deux établissements scolaires de Sudbury en Ontario. Les enfants participants ont complété des questionnaires sur la victimisation par les pairs, les symptômes de dépression, la solitude et cinq dimensions des symptômes d'anxiété (phobie sociale, trouble obsessionnel-compulsif, anxiété de séparation, trouble panique et anxiété généralisée). Les parents ont complété un questionnaire sociodémographique et l'activité physique de leur enfant. Les analyses de corrélations révèlent qu'une faible compétence motrice chez les garçons était significativement associée à plus de symptômes dépressifs, de phobie sociale, d'anxiété de séparation, à la solitude et à la victimisation par les pairs. Chez les filles, une faible compétence motrice était significativement associée aux symptômes d'anxiété de séparation et à la solitude. Aucunes corrélations significatives n'ont été trouvées entre la compétence motrice, le poids, et la participation à l'activité physique. Ces résultats suggèrent que (1) les garçons moins compétents au niveau moteur semblent faire l'expérience de plus de difficultés d'ajustement social et être davantage victimes d'intimidation que les filles et (2) que les enfants éprouvent des problèmes d'ajustement social dès l'âge de 7 ans alors qu'ils commencent à établir leurs premières relations sociales. D’autres recherches seront nécessaires pour valider ces résultats. 


\section{Introduction}

Mastery of gross motor skills is a prerequisite to engage successfully in physical activities throughout the lifespan and is an important correlate to many health-related behaviours and outcomes and have an especially important connection with psychosocial wellbeing (Skinner \& Piek, 2001; Piek, Baynam \& Barrett, 2006). According to the most commonly reported prevalence rates, 5-6\% of children meet the diagnostic criteria for developmental coordination disorder (DCD) (APA, 2013), which is broadly defined as a marked impairment in the development of motor coordination (APA, 2013). This represents approximately 215,000 Canadian children (Statistics Canada, 2016). Moreover, children between the $5^{\text {th }}$ and $15^{\text {th }}$ percentile on motor competence are considered to have borderline motor impairment (Henderson \& Sugden, 1992). Children with low motor competence experience many negative psychosocial consequences that include withdrawal, social isolation and social problems (Chen, Tseng, Hu, \& Cermak, 2009, Smyth \& Anderson, 2000; Schoemaker \& Kalverboer, 1994), less acceptance by peers, fewer playmates, less likely to be asked to play with other children, (Schoemaker \& Kalverboer, 1994) and less social support (Skinner \& Piek, 2001). Other studies show that these children are more victimized by their peers (Campbell, Missiuna \& Vaillancourt, 2012) and have increased internalizing problems such as anxiety and depression (Skinner \& Piek, 2001; Francis \& Piek, 2003; Tseng, Howe, Chuang, \& Hsieh, 2007; Cairney, Rigoli, \& Piek, 2013).

Although research strongly suggests an important relationship between motor competence and psychosocial adjustment, the pathway between low motor competence and psychosocial problems is still poorly understood (Cairney et al. 2013). A theoretical framework first coined by Cairney, Veldhuizen and Szatmari (2010) and later elaborated by Cairney et al. (2013) known as the Elaborated Environmental Stress Hypothesis, posits that indirect or mediating factors precede the psychosocial problems that eventually manifest themselves due to low motor competence. The authors suspected that secondary stressors may contribute to anxiety, depression and loneliness experienced by children with low motor competence. For example, a study by Piek et al. (2007) reported that a child with developmental coordination disorder had more depressive symptoms than their monozygotic twin without DCD. They suggested that unique environmental experiences, such as negative feedback from peers and poor self-perceptions may be reasons why children with low motor competence are predisposed to psychosocial adjustment problems (Piek et al. 2007). Indeed, a handful of longitudinal studies highlight this as well. Piek, Barrett, Smith, Rigoli, \& Gasson (2010) found that inconsistent gross motor scores between the ages of 4 months and 4 years predicted the degree of anxious and depressive symptoms between the ages of 6 and 12 years. Furthermore, Lingam et al. (2012) showed that children with DCD at 7 years of age had a significantly higher risk of self-reporting depression symptoms and parent-reporting mental health problems at 10 years of age. These studies imply that not only are children with low motor competence manifesting psychosocial adjustment problems as a result of their impairments, but also are doing so because of specific negative experiences. 
Most research evaluating the relationship between motor competence and psychosocial adjustment have included children with motor deficits (Skinner \& Piek, 2001; Dewey, Kaplan, Crawford, \& Wilson, 2002; Poulsen, Ziviani, Cuskelly, \& Smith, 2007), which ignores a population of children that are at a sub-clinical level for DCD. Research has shown that no matter the severity of the motor impairments, children are at risk of experiencing different types of problems related to behaviour and adjustment (Schoemaker \& Kalverboer, 1994; Dewey et al. 2002). It has also been suggested that children with subthreshold symptoms of mental health disorders are understudied (Polanczyk, Salum, Sugaya, Caye, \& Rohde, 2015), which could also be extended to physical disorders. Wassenberg et al. (2005) explained it quite effectively by stating that motor skills are better studied as a continuum rather than a dichotomy. It has been suggested that cognitive processes are better understood when studied in normative samples (Roebers \& Kauer, 2009). By extension, a better understanding of children with DCD can be garnered (Roebers \& Kauer, 2009) compared to testing children at the extreme ends of the motor skill spectrum. This can usually result in overestimating the relationship between motor competence and psychosocial adjustment problems (Rigoli, Piek, \& Kane, 2012).

More recent studies have used normative samples to look at this relationship in order to understand the full spectrum of motor skills. Rigoli et al. (2012) and Mancini et al. (2016) tested the relationship between motor competence and psychosocial adjustment problems in a normative sample of adolescents. In addition, Piek et al. (2010) gathered participants from a larger study for which motor skills were not the main focus to test the relationship between motor skills and psychosocial adjustment across the full spectrum of functioning. These studies provide evidence to support the notion that a negative linear relationship exists between motor competence and psychosocial wellbeing. Normative and non-clinical studies on child populations, which are scarce, will help explore this concept further.

In the current study, peer victimization, a component derived from the model, is tested as a secondary stressor. Children with low motor competence are often unsuccessful when trying to perform in daily activities that require a certain level of motor skill, making them an easy target to aggressors because of their observable impairment (Vessey, Duffy, O'Sullivan, \& Swanson, 2004). In Western society, value is placed on skillfulness (Shoemaker \& Kalverboer, 1994). In this context, some studies have demonstrated that children with low motor competency experience more peer victimization than their peers with higher motor competency (Campbell et al. 2012) and are less preferred by their peers in both play and classroom settings (Livesey, Lum Mow, Toshack, \& Zheng, 2011). Research has shown that peer victimization can be very serious, especially in terms of psychosocial functioning (Hawker \& Boulton, 2000). For example, victimized children are more likely to suffer from internalizing problems such as symptoms of depression (Austin \& Joseph, 1996), anxiety (Hawker \& Boulton, 2000), feelings of loneliness (Boulton \& Underwood, 1992; Crick \& Bigbee, 1998) and emotional distress (Crick \& Bigbee, 1998). Evidence points toward a link between motor competence, peer relationships and psychosocial adjustment (Campbell, et al. 2012, Piek, Barrett, Allen, Jones, \& Louise 2005; Vannatta, Gartstein, Zeller, \& Noll, 2009), although more research is required. 
Another secondary stressor identified in the model, and included in the current study, is weight status (Cairney et al. 2013). It has been shown that low motor competent children participate less in physical activity (Cantell, Crawford \& Tish Doyle-Baker, 2008; Cairney et al. 2005b), which may result in overweight and obesity (Cairney et al., 2005a). Children who are overweight or obese are less inclined to participate in physical activity (Trost, Sirard, Dowda, Pfeiffer, \& Pate, 2003), which may contribute to acquiring fewer motor experiences and thus retarding motor development (Morano, Colella \& Caroli, 2011). Obesity in itself increases the risk of experiencing peer-related difficulties (Pitrou, Shojaei, Wazana, Gilbert, \& KovessMasféty, 2010). In fact, Puhl et al. (2016) reported that weight-based bullying is the most prevalent form of bullying across all countries compared to any other type of bullying. Although the literature is somewhat inconclusive about psychosocial problems related to obesity in children (Erickson, Robinson, Haydel, \& Killen, 2000; Quek et al. 2017), it has been suggested that obesity is linked to anxiety (Vila et al. 2004; Esposito et al. 2014), depressive symptoms (Csábi, Tényi, \& Molnár, 2000; Esposito et al. 2014), and loneliness (Mériaux, Berg, \& Hellström, 2010).

Based on the literature, it can be suggested that psychosocial adjustment problems, peer related difficulties, physical inactivity and obesity can arise as a consequence of motor skill deficiency. However, the studies we reviewed only offer a limited understanding of the interconnections between these constructs. The abovementioned literature review demonstrates that low motor competence is not the only reason these children experience more psychosocial adjustment problems than their peers. There seem to be secondary stressors that contribute to these problems acting as either direct or indirect consequences to low motor competence. Furthermore, the extent that children's characteristics, such as their specific degree of motor competence, affect their psychosocial adjustment remains an open question.

The current study aims at testing four hypotheses. Hypothesis one states that there will be a negative linear relationship between motor skills and psychosocial adjustment. Higher motor competence will generate fewer psychosocial adjustment problems and will move along a continuum to lower motor competence generating more psychosocial adjustment problems. Hypothesis two states that children with lower motor competence will experience more peer victimization than their more competent peers, exhibiting a negative linear relationship. Hypothesis three states that children with lower motor competence will be more obese and/or participate less in physical activity than their more competent peers. Hypothesis four states that more peer victimization and higher weight status will generate more psychosocial problems.

\section{Methods}

\section{Participants}

A total of 51 children $(45.1 \%$ female) between 7 and 10 years of age $(\mathrm{M}=8.39$ years; $\mathrm{SD}=$ 1.11) and their parent participated in this study. Children were recruited from a French-speaking 
public school and parents with children between the ages of 7 and 10 from a local post-secondary institution. Nearly three-quarters of parents reported having an annual household income of $\$ 100,000$ or more $(n=38 ; 74.5 \%)$ and nearly three-quarters of parents reported having completed post-secondary education $(\mathrm{n}=35 ; 71.4 \%)$.

\section{Procedure}

Permission to collect data was granted by the University's Research Ethics Board. Parents were asked to complete the following: (1) consent form, (2) physical activity readiness questionnaire for children, and (3) sociodemographic questionnaire. During the first phase of testing, a oneon-one session was conducted for each child participant to complete the psychosocial questionnaires in a private room. The researcher explained the procedure to each child, making sure the child fully understood, provided assent and felt comfortable answering the questions. The Revised Child Anxiety and Depression Scale, the Loneliness and Social Dissatisfaction Scale and the modified Schwartz Peer Victimization Scale were administered.

During the second stage the researcher and one or two research assistants administered the Test of Gross Motor Development-3 (TGMD-3) in a gymnasium. Both the lead researcher and research assistants were trained on the TGMD-3. The main researcher explained and demonstrated the movement skills as outlined in the TGMD-3, while the research assistants scored the child according to the test criteria.

\section{Measures}

\section{Test of Gross Motor Development-3}

The Test of Gross Motor Development-3 (TGMD-3) by Ulrich (2013) was used and assesses 13 fundamental movement skills with both locomotor and ball skills subscales. In a recent evaluation of the psychometric properties of the TGMD-3, Ulrich and Webster (2017) report that the test has a high degree of reliability and validity, including excellent internal consistency and test-retest reliability. Cronbach's $\alpha$ was between 0.95 and 0.98 across all ages. This preliminary study did not however report on whether there were significant differences in motor skill development after the age of 7. As children typically develop to a skillful (but not necessarily mature) level in most of the fundamental motor skills by the age of 7 (Gabbard, 2011), we interpreted the scores similarly for each age group.

\section{$\underline{\text { Revised Child Anxiety and Depression Scale }}$}

The Revised Child Anxiety and Depression Scale (RCADS) by Chorpita, Yim, Moffitt, Umemoto and Francis (2000) was used to assess anxiety and depression symptoms. The questionnaire has 47 items with subscales that include symptoms associated with separation anxiety disorder, social phobia, generalized anxiety disorder, panic disorder, obsessive- 
compulsive disorder, and major depressive disorder. Validation studies suggest that the test structure is consistent with DSM-IV anxiety disorders and depression. However, these measures cannot be used as diagnostic tool for the purpose of the current research and the authors refer to symptoms rather than the diagnostic labels. Alpha coefficients for each subscale ranged from $\alpha=$ 0.71-0.85 (Chorpita et al. 2000). Cronbach's $\alpha$ for the complete test in this sample was 0.90 and for each subscale as follows: 0.77 for separation anxiety disorder, 0.77 for social phobia, 0.60 for generalized anxiety disorder, 0.76 for panic disorder, 0.69 for obsessive-compulsive disorder, and 0.56 for major depressive disorder.

\section{$\underline{\text { Loneliness and Social Dissatisfaction Scale }}$}

The Loneliness and Social Dissatisfaction Scale by Cassidy \& Asher (1992) is a 24-item selfreport scale containing 16 items measuring perceptions of loneliness and eight filler items. Higher scores indicated lower feelings of loneliness. This questionnaire has been shown to have excellent psychometric properties, high internal consistency and good test-retest reliability (Goossens \& Beyers, 2002). In a review of loneliness measures by Goossens and Beyers (2002), Cronbach's $\alpha$ in three separate samples exceeded 0.80. Cronbach's $\alpha$ in this sample was 0.72 .

\section{$\underline{\text { Schwartz Peer Victimization Scale (Modified) }}$}

The Schwartz Peer Victimization Scale (SPVS) is a 5-item self-report measure of peer victimization (Schwartz, Farver, Change, \& Lee-Shin, 2002). For the purpose of this study, it was modified to include two further items ("How often do other kids ignore you?" and "How often do other kids say mean things to you online?"). These items were added to measure passive aggressive behaviour (relational victimization) and cyberbullying due to the increasing use of electronics to target individuals (Lamb, Pepler \& Craig, 2009). The measure has good internal consistency $(\alpha=0.75)$ and correlated modestly and positively with teacher $(R=.32, p>$ $.001)$ and peer reports $(R=.39, p>.001)$ of victimization (Schwartz et al., 2002). Cronbach's $\alpha$ in this sample was 0.87 .

\section{Physical Activity Questionnaire for Parents}

Within the questionnaire, parents were asked to indicate the total amount of time, on average, that their child participated in daily physical activity. The items were rated on a four-point Likert scale as follows: 1) Less than 30 minutes per day, 2) 30 to 60 minutes per day, 3) 60 to 120 minutes per day, and 4) 120 minutes or more per day $(\mathrm{M}=2.8 ; \mathrm{SD}=.72)$. Based on the physical activity guidelines for children and youth (Tremblay et al. 2011; WHO, 2010), the scale was dichotomized into less than an hour of physical activity per day $(\mathrm{n}=22 ; 43.1 \%)$ and one hour or more of physical activity per day $(\mathrm{n}=29 ; 56.9 \%)$. 


\section{$\underline{\text { Anthropometric measurements }}$}

Body weight (to the nearest $0.1 \mathrm{~kg}$ ) and standing height (to the nearest $\mathrm{cm}$ ) were determined using a scale and a portable tape measure. Weight status for each child was determined using the body mass index (BMI). Each child was classified in one of the three following categories: 'normal weight' (between $3^{\text {rd }}$ and $85^{\text {th }}$ percentile), 'overweight' (between $85^{\text {th }}$ and $97^{\text {th }}$ percentile) or obese $\left(>99.9^{\text {th }}\right.$ percentile). Overall, thirty-seven children were considered normal weight $(72.5 \%)$, whereas ten children were overweight $(19.6 \%)$ and four children were obese $(7.8 \%)$. There were no significant gender differences in the proportion of children who were normal weight and those who were overweight and obese, $\chi^{2}(1)=.19, p=.67$.

\section{Results}

All statistical analyses were performed using the Statistical Package for the Social Sciences, SPSS-20. We first conducted a series of two-way ANOVAs to compare boys and girls on psychosocial adjustment variables and gross motor skills. Second, we conducted Pearson product-moment correlations to test our four hypotheses postulating significant relationships between psychosocial adjustment measures, gross motor skills and children's characteristics.

Table 1 shows descriptive statistics comparing male and female participants on psychosocial adjustment variables. We did not find significant gender differences on peer victimization $\left(F_{(1,49)}=2.31, p=.14\right)$, loneliness $\left(F_{(1,49)}=.75, p=.39\right)$, depression symptoms $\left(F_{(1,49)}=\right.$ $1.19, p=.28)$, generalized anxiety symptoms $\left(F_{(1,49)}=.15, p=.71\right)$, obsessive-compulsive symptoms $\left(F_{(1,49)}=.45, p=.50\right)$, panic disorder symptoms $\left(F_{(1,49)}=.02, p=.90\right.$, separation anxiety symptoms $\left(F_{(1,49)}=.01, p=.92\right)$, and on social phobia symptoms $\left(F_{(1,49)}=.11, p=.74\right)$. Table 2 shows means, standard deviations, and F-values comparing male and female participants on gross motor skills. We first found significant gender differences in the ball skills subscale $\left(F_{(1,49)}=\right.$ 9.72, $p>.01)$, with boys exhibiting higher skills $(\mathrm{M}=46.4, \mathrm{SD}=7.8)$ than girls $(\mathrm{M}=39.4, \mathrm{SD}=$ 8.0). Second, we found significant gender differences on the total motor score $\left(F_{(1,49)}=4.35, p>\right.$ $.05)$, with boys exhibiting higher skills $(\mathrm{M}=83.3, \mathrm{SD}=11.9)$ than girls $(\mathrm{M}=76.4, \mathrm{SD}=11.2)$. However, no significant differences were noted between boys and girls on the locomotor skills subscale $\left(F_{(1,49)}=.01, p=.93\right)$. 
Table 1

Means (SD) and F-value for psychological variables

\begin{tabular}{l|llc} 
MEASURES/VARIABLES & FEMALE & MALE & \multicolumn{1}{l}{$\boldsymbol{F}$} \\
\hline $\begin{array}{l}\text { SCHWARTZ PEER } \\
\text { VICTIMIZATION }\end{array}$ & $1.5(.5)$ & $1.8(.8)$ & 2.31 \\
$\begin{array}{l}\text { LONELINESS AND SOCIAL } \\
\text { DISSATISFACTION }\end{array}$ & $2.5(.2)$ & $2.4(.3)$ & 0.75 \\
MAJOR DEPRESSION & $8.2(2.7)$ & $6.8(3.8)$ & 1.19 \\
GENERALIZED ANXIETY & $6.8(3.6)$ & $6.4(2.5)$ & 0.15 \\
OBSESSIVE-COMPULSIVE & $6.7(3.8)$ & $6.2(4.1)$ & 0.45 \\
PANIC DISORDER & $5.9(4.5)$ & $4.9(4.2)$ & 0.02 \\
SEPARATION ANXIETY & $7.0(4.9)$ & $5.1(4.4)$ & 0.01 \\
SOCIAL PHOBIA & $11.0(5.4)$ & $8.8(4.9)$ & 0.11 \\
$* P<0.05, * * P<0.01, * * * P<0.001$. & & &
\end{tabular}

Table 2.

Means (SD) and F-value for gross motor skills

\begin{tabular}{l|lll} 
MEASURES/VARIABLES & FEMALE & MALE & $\boldsymbol{F}$ \\
\hline BALL SKILLS & $39.4(8.0)$ & $46.4(7.8)$ & $9.72 * *$ \\
LOCOMOTOR SKILLS & $37.0(4.9)$ & $36.9(6.2)$ & 0.01 \\
TOTAL SCORES & $76.4(11.2)$ & $83.3(11.9)$ & $4.35^{*}$
\end{tabular}

$* P<0.05, * * P<0.01, * * * P<0.001$

We performed Pearson product-moment correlation analyses to examine associations between all the variables. The analyses were conducted separately for boys and for girls. The results are shown in Table 3 and 4. Our first hypothesis stated that there would be a negative linear relationship between motor skills and the psychosocial adjustment variables. Correlation analyses were conducted between motor competence and psychosocial variables (i.e. symptoms of depression, generalized anxiety, obsessive-compulsive, panic disorder, separation anxiety, social phobia, and loneliness). For boys, it was found that total motor competence was negatively associated with depressive symptoms $(R=-.72, p<.001)$, separation anxiety symptoms $(R=-$ $.47, p<.05)$ and social phobia symptoms $(R=-.54, p<.01)$. Third, we found a significant positive correlation between the ball skills subscale and loneliness $(R=.44, p<.05)$. Higher scores on the Loneliness and Social Dissatisfaction Scale indicate less overall loneliness which means that higher scores on the ball skills subscale are associated with less reported loneliness. Finally, for our boy's subsample, motor performance did not significantly correlate with the other items in the RCADS. In girls, we first found a positive and significant correlation between the ball skills subscale and reported loneliness $(R=.45, p<.05)$. Second, we found a significant negative correlation between the locomotor subscale and separation anxiety symptoms $(R=-.44, p<.05)$. For girls, motor performance did not significantly correlate with 
the other items in the RCADS. These results support our hypothesis on a large portion of the variables.

Our second hypothesis stated that children with lower motor competence would experience more peer victimization than their more competent peers. To test this hypothesis, we conducted Pearson product-moment correlations between motor competence and reported peer victimization. For boys, we found a significant negative correlation between motor competence total score and reported peer victimization $(R=-.44, p<.05)$ and, more specifically with the locomotor skills subscale $(R=-.49, p<.01)$. We did not find any significant correlation between motor competence and reported peer victimization in girls $(R=-.19, p=.39)$. Therefore, our hypothesis was only supported for boys in this sample.

Our third hypothesis stated that children with lower motor competence would be more overweight and/or participate in less physical activity than their more competent peers. To test this hypothesis, we conducted Pearson product-moment correlations between physical activity (as reported by parents), motor competence and weight status. In both boys and girls, we did not find any significant correlation between motor competence and physical activity (boys: $R=.29$, $p=.15$; girls: $R=.40, p=.06$ ) or weight status (boys: $R=-.07, p=.74$; girls: $R=.07, p=$ .75). Therefore, our hypothesis was not supported.

Our final hypothesis stated that more peer victimization and higher weight status would generate more psychosocial adjustment problems. To test this hypothesis, we conducted Pearson product-moment correlations between reported peer victimization and the psychosocial adjustment variables, as well as between weight status and the psychosocial adjustment variables. For boys, reported peer victimization had a significant positive correlation with all psychosocial variables except for depression symptoms $(R=.29, p=.14)$ and loneliness $(R=-$ $.10, p=.61)$; that is, generalized anxiety symptoms $(R=.62, p<.001)$, obsessive compulsive symptoms $(R=.37, p<.05)$, panic disorder symptoms $(R=.43, p<.05)$, separation anxiety symptoms $(R=.57, p<.01)$ and social phobia symptoms $(R=.58, p<0.001)$. For girls, reported peer victimization was found to have a positive correlation with depression symptoms $(\mathrm{R}=.58, p<.05)$, and social phobia symptoms $(R=.49, p<.01)$. No correlations were found between peer victimization and the remaining items in the RCADS. For boys, no correlations were found between weight status and the psychosocial variables. For girls, no correlations were found between weight status and the psychosocial adjustment variables. However, obsessivecompulsive symptoms were found to have a negative correlation with weight status $(R=-.52, p$ $<.05)$. Our hypothesis was supported when comparing peer victimization with the psychosocial adjustment variables but was not supported when comparing weight status with the psychosocial adjustment variable. 
Diversity of Research in Health Journal /Revue de la Diverstité de la Recherche en Santé

Vol 2, September 2018 - ISSN 2561-1666

DOI 10.28984/drhj.v2i0.240

Table 3: Correlations of Study Variables (Male)

\begin{tabular}{|c|c|c|c|c|c|c|c|c|c|c|c|c|c|c|}
\hline 3 Scale & 1 & 2 & 3 & 4 & 5 & 6 & 7 & 8 & 9 & 10 & 11 & 12 & 13 & 14 \\
\hline $\begin{array}{l}1 \text { - Major } \\
\text { Depression }\end{array}$ & 1.00 & & & & & & & & & & & & & \\
\hline $\begin{array}{l}2 \text { - } \\
\text { Generalized } \\
\text { Anxiety }\end{array}$ & .26 & 1.00 & & & & & & & & & & & & \\
\hline $\begin{array}{l}3 \text { - Obsessive } \\
\text { Compulsive }\end{array}$ & .18 & .23 & 1.00 & & & & & & & & & & & \\
\hline $\begin{array}{l}4 \text { - Panic } \\
\text { Disorder }\end{array}$ & .25 & .36 & .37 & 1.00 & & & & & & & & & & \\
\hline $\begin{array}{l}5 \text { - Separation } \\
\text { Anxiety }\end{array}$ & .30 & $.44 *$ & $.55 * *$ & $.58 * * *$ & 1.00 & & & & & & & & & \\
\hline $\begin{array}{l}6 \text { - Social } \\
\text { Phobia }\end{array}$ & $.47 *$ & $.63^{* * *}$ & .28 & $.56 * *$ & $.53 * *$ & 1.00 & & & & & & & & \\
\hline $\begin{array}{l}7 \text { - Peer } \\
\text { Victimization }\end{array}$ & .29 & $.62 * * *$ & $.37 *$ & $.43 *$ & $.57 * *$ & $.58 * * *$ & 1.00 & & & & & & & \\
\hline 8 - Loneliness & $-.57 * *$ & -.26 & .24 & -.02 & -.05 & -.12 & -.10 & 1.00 & & & & & & \\
\hline 9 - Age & -.33 & -.06 & $-.61 * * *$ & -.25 & -.31 & -.14 & -.33 & .09 & 1.00 & & & & & \\
\hline $\begin{array}{l}10 \text { - TGMD-3 } \\
\text { Ball Skills }\end{array}$ & $-.79 * * *$ & -.31 & -.24 & -.27 & -.37 & $-.56 * *$ & -.28 & $.44 *$ & $.43 *$ & 1.00 & & & & \\
\hline $\begin{array}{l}11 \text { - TGMD-3 } \\
\text { Locomotor } \\
\text { Skills }\end{array}$ & $-.37 *$ & -.27 & -.22 & -.29 & $-0.44 *$ & -.34 & $-.49 * *$ & .23 & .20 & $.43^{*}$ & 1.00 & & & \\
\hline $\begin{array}{l}12 \text { - TGMD-3 } \\
\text { Final Score }\end{array}$ & $-.72 * * *$ & -.34 & -.27 & -.33 & $-.47 *$ & $-.54 * *$ & $-.44 *$ & $.41 *$ & $.39 *$ & $.88 * * *$ & $.80 * * *$ & 1.00 & & \\
\hline $\begin{array}{l}13 \text { - Physical } \\
\text { Activity }\end{array}$ & $-.40 *$ & -.08 & -.26 & -.18 & -.28 & -.21 & -.06 & .01 & .21 & .25 & .24 & .29 & 1.00 & \\
\hline $\begin{array}{l}14 \text { - Weight } \\
\text { Status }\end{array}$ & .00 & -.24 & -.01 & -.20 & .10 & -.17 & -.01 & -.14 & -.12 & -.06 & -.05 & -.07 & .23 & 1.00 \\
\hline
\end{tabular}

$* P<0.05, * * P<0.01, * * * P<0.001$ 
Diversity of Research in Health Journal /Revue de la Diverstité de la Recherche en Santé Vol 2, September 2018 - ISSN 2561-1666_DOI 10.28984/drhj.v2i0.240

Table 4. Correlations of Study Variables (Female)

\begin{tabular}{|c|c|c|c|c|c|c|c|c|c|c|c|c|c|c|}
\hline 4 Scale & 1 & 2 & 3 & 4 & 5 & 6 & 7 & 8 & 9 & 10 & 11 & 12 & 13 & 14 \\
\hline $\begin{array}{l}\text { - Major } \\
\text { Depression }\end{array}$ & 1.00 & & & & & & & & & & & & & \\
\hline $\begin{array}{l}2 \text { - Generalized } \\
\text { Anxiety }\end{array}$ & $.54 * *$ & 1.00 & & & & & & & & & & & & \\
\hline $\begin{array}{l}3 \text { - Obsessive } \\
\text { Compulsive }\end{array}$ & $.56^{* * *}$ & $.57 * *$ & 1.00 & & & & & & & & & & & \\
\hline $\begin{array}{l}4 \text { - Panic } \\
\text { Disorder }\end{array}$ & $.57 * *$ & $.52 *$ & $.70 * * *$ & 1.00 & & & & & & & & & & \\
\hline $\begin{array}{l}5 \text { - Separation } \\
\text { Anxiety }\end{array}$ & .19 & $.44 *$ & .35 & .29 & 1.00 & & & & & & & & & \\
\hline $\begin{array}{l}6 \text { - Social } \\
\text { Phobia }\end{array}$ & $.53 * *$ & $.67 * * *$ & $.48 *$ & .36 & $.50 *$ & 1.00 & & & & & & & & \\
\hline $\begin{array}{l}7 \text { - Peer } \\
\text { Victimization }\end{array}$ & $.58 * *$ & .38 & .30 & .30 & .36 & $.49 *$ & 1.00 & & & & & & & \\
\hline 8 - Loneliness & -.17 & -.19 & -.28 & -.34 & -.10 & -.18 & -.19 & 1.00 & & & & & & \\
\hline 9-Age & $.57 * *$ & .30 & $.46 *$ & $.64 * * *$ & .27 & .22 & $.43 *$ & -.05 & 1.00 & & & & & \\
\hline $\begin{array}{l}10 \text { - TGMD-3 } \\
\text { Ball Skills }\end{array}$ & .05 & .06 & .12 & .40 & .11 & .00 & -.07 & $.45^{*}$ & .35 & 1.00 & & & & \\
\hline $\begin{array}{l}11 \text { - TGMD-3 } \\
\text { Locomotor } \\
\text { Skills }\end{array}$ & -.09 & -.12 & -.02 & .00 & $-.44 *$ & -.33 & -.32 & .39 & .03 & $.47 *$ & 1.00 & & & \\
\hline $\begin{array}{l}12 \text { - TGMD-3 } \\
\text { Final Score }\end{array}$ & -.00 & -.01 & .08 & .283 & -.17 & -.15 & -.19 & $.49 *$ & .26 & $.92 * * *$ & $.78 * * *$ & 1.00 & & \\
\hline $\begin{array}{l}13 \text { - Physical } \\
\text { Activity }\end{array}$ & 0.01 & 0.12 & -.03 & .10 & .04 & .06 & .11 & .14 & .22 & $.43 *$ & .21 & .40 & 1.00 & \\
\hline $\begin{array}{l}14 \text { - Weight } \\
\text { Status }\end{array}$ & -.26 & -0.33 & $-.52 *$ & -.24 & -.20 & -.34 & .09 & .35 & -.09 & .05 & .08 & .07 & .39 & 1.00 \\
\hline
\end{tabular}

$* P<0.05, * * P<0.01, * * * P<0.001$ 


\section{Discussion}

The aim of this study was to examine the relationship between aspects of gross motor skills, selfreported peer victimization, and self-reported psychosocial adjustment variables (i.e. anxiety, depression, loneliness), physical activity and weight status in a sample of sub-clinical, normally developing children aged 7 to 10 years. In boys, lower motor competence was directly correlated with higher levels of depressive symptoms. These findings are consistent with previous research such as that of Francis \& Piek (2003) which investigated the relationships between perceived social support and self-worth on depression symptoms in children with DCD. Their findings indicated that depression symptoms were greater in the DCD group compared to their control group. Even though our sample in the current study was sub-clinical, this relationship was confirmed, suggesting that depression symptoms do not only affect boys with DCD but also boys that may not necessarily meet clinical cut-point criteria. In addition, higher motor competence corresponded to fewer depressive symptoms, providing a unique perspective on the relationship between motor competence and psychosocial adjustment.

Social phobia symptoms were also found to correlate with low motor competence in boys in the current study. These results are in alignment with those of Pratt and Hill (2011) who reported nearly $30 \%$ of the children in their DCD group experienced social phobia at a clinically significant level. This can be explained by a number of studies that suggest that children with low motor competence have lower perceptions of social support (Skinner \& Piek, 2001), and social acceptance (Schoemaker \& Kalverboer, 1994), and are more rejected by their peers (Livesey et al. 2011) causing social environments to be feared. In the present study, separation anxiety symptoms correlated negatively with total motor competence in boys and locomotor competence in girls, which has not been reported in earlier studies. This finding suggests that boys and girls with low motor competency may suffer from attachment issues. In their study, Pratt and Hill (2011) reported panic anxiety as the most prominent form of anxiety in their sample, with almost $50 \%$ of their DCD group reporting higher levels of panic, a finding that was not supported in the present study. However, they did remark on the variability in anxiety disorders in children with DCD. They looked at individual differences in their data and noted that the types of anxiety that children reported were not always the same (Pratt \& Hill, 2011). That is to say, psychosocial adjustment problems may be vastly different across groups and individuals, making it likely that different studies will find varying forms of psychosocial adjustment problems to be at the forefront. Studies such as those of Mancini et al. (2016), Rigoli et al. (2012), and Pearsall-Jones et al. (2011) measured separation anxiety as a component of their total anxiety scores although they did not report on the type of anxiety specifically. In all of these studies, total anxiety scores were always higher in children with low motor competence scores. From a different perspective, Vila and colleagues (2004) had similar findings when they studied children and adolescents suffering from overweight or obesity. Thirty-two percent of their sample had at least one psychiatric anxiety disorder with social phobia and separation

anxiety appearing very frequently. Their interpretation of the results would be similar to ours in that these children fear social environments due to criticism from peers (whether because of their 
weight or their motor competence) and for that reason, are more dependent on family and parental figures (Vila et al. 2004). This creates a cycle of social avoidance, further reinforcing dependence on close family members, and heightening anxiety related to social contact (Vila et al. 2004). Furthermore, because the emphasis to succeed in physical activities is very high and almost every social activity in a child's life revolves around play, children with low motor competence can be incessantly fearful.

We found that self-reported peer victimization negatively correlated with motor competence for boys only. Although some researchers have found that girls and boys are equally likely to be victimized (Boulton \& Smith, 1994; Jimerson, Swearer, \& Espelage, 2010), others have suggested that boys are generally more victimized than girls (Nansel et al. 2001; Iossi Silva et al. 2013). A possible explanation resides in the fact that, historically and in modern day society, sports have been strongly associated with masculinity (Adams, Anderson, McCormack, 2010). In addition, populations have been socialized to see sports as a male dominant activity (Senne, 2016), and boys have been known to place more value on sport than girls (Lee, Carter, \& Xiang, 1995). These social constructs may explain why boys in our study reported more victimization and anxiety than their female counterparts. Some research findings support this explanation. For example, Livesey et al. (2011) found that boys with lower motor competence were less preferred by their peers than were girls when scored on a peer rating scale in both play and classroom settings. Sigurdsson and colleagues (2002) found that mothers of boys with low motor competence were three times more likely to report their sons having anxiety problems at ages 11 and 16 whereas no effect was found for girls.

Another notable finding was that higher reported loneliness in boys and girls was associated with lower motor competence. Although very few studies have looked at reports of loneliness in this population, a few have described similar findings (Poulsen et al. 2007; Schoemaker \& Kalverboer, 1994; Smyth \& Anderson, 2000). For example, Poulsen et al. (2007) reported that boys with DCD had significantly higher levels of loneliness than their non-DCD counterparts. These boys were also much less likely to participate in both structured and unstructured play activities. Other studies have reported that children with low motor competence report having fewer playmates, are much less likely to be asked to play with other children (Schoemaker \& Kalverboer, 1994) and spend more time alone (Smyth \& Anderson, 2000).

Although most studies have supported the notion that motor competence is significantly related to participation in physical activity (Barnett et al. 2009; Lopes, Rodrigues, Maia, \& Malina 2011; Lubans, Morgan, Cliff, Barnett, \& Okely, 2010; Reillo, Vlahov, Bohren, Leppo, \& Davis, 2010), our study did not support this, nor did it support higher weight status in children with low motor competence. There may be several reasons for this lack of association. First, our sample size is very small, preventing us from comparing our participants according to their weight status, age, gender and, physical activity on motor skills acquisition. Second, it is also possible that our participants weight status did not impact motor skills. This explanation is supported by the findings of Okely, Booth, \& Chey (2004) and Southall, Okely, \& Steele (2004) 
who report that for most age groups, object control skills are unrelated to a child's weight status. However, these studies revealed that contrary to object control, locomotor skills are indeed influenced by weight status, as they report lower skills in the group of children that are overweight (Okely et al. 2004; Southall et al. 2004). Finally, another possible explanation could be the fact that our child participants have not yet reached the point at which their motor skill deficiency has been longstanding enough to acquire more weight.

The current study has several strengths. First, we used a validated direct measurement of gross motor skills, which allows a direct assessment of the child's physical ability. Second, psychological symptoms and peer victimization questionnaires were administered by the researcher to children by mean of a face-to-face interview, which helps avoid errors around comprehension since the child could ask the meaning of a question if needed. Also, another advantage of the one-on-one interview is that the researcher was able to build a strong rapport and deeper level of trust with the child before answering the questions.

The results of the current study must be interpreted with caution in light of several limitations. First, the sample is small and therefore the findings may not be generalizable to a broader segment of the population. Second, we did not use parent and teacher reports as proxies to compare the child's perceptions. Third, the nature of the study required the participant to reveal sensitive and personal information, which may prevent them from fully disclosing their concerns or symptoms. Finally, our sample may have a selection bias, that is, parents of children with moderate to severe motor impairments may have been less inclined to participate for fear of putting their child in a vulnerable situation. 


\section{Conclusion}

This study found statistically significant correlations between motor competence, self-reported peer victimization and many self-reported psychosocial adjustment variables that include depression symptoms, social phobia symptoms, separation anxiety symptoms, and loneliness in boys. Although we did not find similar results in girls, we did find statistically significant correlations between motor competence and separation anxiety symptoms and self-reported loneliness. It is important to raise awareness amongst parents, teachers, and health care professionals about early identification and interventions that could potentially minimize the risks of children experiencing psychosocial adjustment problems associated with this condition. Considering the importance motor coordination plays on activities of daily living and its implications on psychosocial development and wellbeing, early identification and intervention are crucial. Remedial motor skills training would be an important preventative measure taken to avert these outcomes. Habitual motor skills training for all children would also contribute to higher levels of psychosocial adjustment overall due to the negative linear relationship found between these constructs. The role of elementary schools in this training is crucial and a renewed focus on physical education classes with a qualified physical education teacher should be considered a priority. In addition, school boards and their educators should consider the findings of the current research as another argument to promote and include physical education as an important part of the school curriculum. Our findings provide some support for the Elaborated Environmental Stress Hypothesis, however much more research is required. Further research should focus on gathering a larger sample size in order to investigate whether reported peer victimization directly mediates the relationship between motor competence and psychosocial adjustment.

\section{Acknowledgements}

The authors gratefully acknowledge the Consortium national de formation en santé for funding this study. They would also like to extend appreciation to all the educators, parents, and children for their contributions. 


\section{References}

Adams, A., Anderson, E., \& McCormack, M. (2010). Establishing and challenging masculinity: The influence of gendered discourses in organized sport. Journal of Language and Social Psychology, 29(3), 278-300.

American Psychiatric Association (2013). Diagnostic and statistical manual of mental disorders (DSM-5®). Washington, DC: Author.

Austin, S., \& Joseph, S. (1996). Assessment of bully/victim problems in 8 to 11-year-olds. British Journal of Educational Psychology, 66(4), 447-456.

Barnett, L. M., Van Beurden, E., Morgan, P. J., Brooks, L. O., \& Beard, J. R. (2009). Childhood motor skill proficiency as a predictor of adolescent physical activity. Journal of Adolescent Health, 44(3), 252-259.

Boulton, M. J., \& Underwood, K. (1992). Bully/victim problems among middle school children. British Journal of Educational Psychology, 62(1), 73-87.

Boulton, M. J., \& Smith, P. K. (1994). Bully/victim problems in middle-school children: Stability, self-perceived competence, peer perceptions and peer acceptance. British Journal of Developmental Psychology, 12(3), 315-329.

Cairney, J., Hay, J. A., Faught, B. E., \& Hawes, R. (2005a). Developmental coordination disorder and overweight and obesity in children aged 9-14 y. International Journal of Obesity, 29(4), 369-372.

Cairney, J., Hay, J. A., Faught, B. E., Wade, T. J., Corna, L., \& Flouris, A. (2005b).

Developmental coordination disorder, generalized self-efficacy toward physical activity, and participation in organized and free play activities. The Journal of Pediatrics, 147(4), 515-520.

Cairney, J., Rigoli, D., \& Piek, J. (2013). Developmental coordination disorder and internalizing problems in children: the environmental stress hypothesis elaborated. Developmental Review, 33(3), 224-238.

Cairney, J., Veldhuizen, S., \& Szatmari, P. (2010). Motor coordination and emotional-behavioral problems in children. Current Opinion in Psychiatry, 23(4), 324-329.

Campbell, W. N., Missiuna, C., \& Vaillancourt, T. (2012). Peer victimization and depression in children with and without motor coordination difficulties. Psychology in the Schools, 49(4), 328-341.

Cantell, M., Crawford, S.G., \& Tish Doyle-Baker, P.K. (2008). Physical fitness and health indices in children, adolescents and adults with high or low motor competence. Human Movement Science, 27(2), 344-362.

Cassidy, J., \& Asher, S. R. (1992). Loneliness and peer relations in young children. Child Development, 63(2), 350-365.

Chen, Y. W., Tseng, M. H., Hu, F. C., \& Cermak, S. A. (2009). Psychosocial adjustment and attention in children with developmental coordination disorder using different motor tests. Research in Developmental Disabilities, 30(6), 1367-1377. 
Chorpita, B. F., Yim, L., Moffitt, C., Umemoto, L. A., \& Francis, S. E. (2000). Assessment of symptoms of DSM-IV anxiety and depression in children: A revised child anxiety and depression scale. Behaviour Research and Therapy, 38(8), 835-855.

Crick, N. R., \& Bigbee, M. A. (1998). Relational and overt forms of peer victimization: a multiinformant approach. Journal of Consulting and Clinical Psychology, 66(2), 337347.

Dewey, D., Kaplan, B. J., Crawford, S. G., \& Wilson, B. N. (2002). Developmental coordination disorder: associated problems in attention, learning, and psychosocial adjustment. Human Movement Science, 21(5), 905-918.

Erickson, S. J., Robinson, T. N., Haydel, K. F., \& Killen, J. D. (2000). Are overweight children unhappy?: Body mass index, depressive symptoms, and overweight concerns in elementary school children. Archives of Pediatrics and Adolescent Medicine, 154(9), 931-935.

Esposito, M., Gallai, B., Roccella, M., Marotta, R., Lavano, F., Lavano, S. M., .. \& Carotenuto, M. (2014). Anxiety and depression levels in prepubertal obese children: a case-control study. Neuropsychiatric Disease and Treatment, 10, 1897-1902.

Francis, M., \& Piek, J. (2003). The effects of perceived social support and self-worth on depressive symptomatology in children with and without developmental coordination disorder (DCD). In Proceedings of the 38th APS annual conference (pp. 70-74).

Gabbard, C.P. (2011). Lifelong Motor Development, $6^{\text {th }}$ ed. San Francisco, CA: Pearson Benjamin Cummings.

Gallahue, D.L., Ozmun J.C. (2006) Understanding Motor Development: Infants, Children, Adolescents, Adults, $6^{\text {th }}$ ed. Boston, MA: McGraw-Hill.

Goossens, L., \& Beyers, W. (2002). Comparing measures of childhood loneliness: Internal consistency and confirmatory factor analysis. Journal of Clinical Child and Adolescent Psychology, 31(2), 252-262.

Hawker, D. S., \& Boulton, M. J. (2000). Twenty years' research on peer victimization and psychosocial maladjustment: A meta-analytic review of cross-sectional studies. The Journal of Child Psychology and Psychiatry and Allied Disciplines, 41(4), 441-455.

Henderson, S. E., \& Sugden, D. A. (1992). Movement Assessment Battery for Children. Kent, England: Psychological Corporation.

Iossi Silva, M. A., Pereira, B., Mendonça, D., Nunes, B., \& Oliveira, W. A. D. (2013). The involvement of girls and boys with bullying: an analysis of gender differences. International Journal of Environmental Research and Public Health, 10(12), 6820-6831.

Jimerson, S. R., Swearer, S. M., \& Espelage, D. L. (2010). Handbook of bullying in schools: An international perspective. New York, NY: Routledge.

Lamb, J., Pepler, D. J. \& Craig, W. (2009) Approach to bullying and victimization. Canadian Family Physician, 55(4), 356-360. 
Lee, A. M., Carter, J. A., \& Xiang, P. (1995). Children's conceptions of ability in physical education. Journal of Teaching in Physical Education, 14(4), 384-393.

Lingam, R., Jongmans, M. J., Ellis, M., Hunt, L. P., Golding, J., \& Emond, A. (2012). Mental health difficulties in children with developmental coordination disorder. Pediatrics, 129(4), e882-e891.

Livesey, D., Lum Mow, M., Toshack, T., \& Zheng, Y. (2011). The relationship between motor performance and peer relations in 9 to 12-year-old children. Child: Care, Health and Development, 37(4), 581-588.

Lopes, V. P., Rodrigues, L. P., Maia, J. A., \& Malina, R. M. (2011). Motor coordination as predictor of physical activity in childhood. Scandinavian Journal of Medicine \& Science in Sports, 21(5), 663-669.

Lubans, D. R., Morgan, P. J., Cliff, D. P., Barnett, L. M., \& Okely, A. D. (2010). Fundamental movement skills in children and adolescents. Sports Medicine, 40(12), 1019-1035.

Mancini, V. O., Rigoli, D., Heritage, B., Roberts, L. D., \& Piek, J. P. (2016). The relationship between motor skills, perceived social support, and internalizing problems in a community adolescent sample. Frontiers in Psychology, 7, 543.

Mériaux, B. G., Berg, M., \& Hellström, A. L. (2010). Everyday experiences of life, body and well-being in children with overweight. Scandinavian Journal of Caring Sciences, 24(1), 14-23.

Morano, M., Colella, D., \& Caroli, M. (2011). Gross motor skill performance in a sample of overweight and non-overweight preschool children. Pediatric Obesity, 6(S2), $42-46$.

Nansel, T. R., Overpeck, M., Pilla, R. S., Ruan, W. J., Simons-Morton, B., \& Scheidt, P. (2001). Bullying behaviors among US youth: Prevalence and association with psychosocial adjustment. Jama, 285(16), 2094-2100.

Okely, A. D., Booth, M. L., \& Chey, T. (2004). Relationships between body composition and fundamental movement skills among children and adolescents. Research Quarterly for Exercise and Sport, 75(3), 238-247.

Pearsall-Jones, J. G., Piek, J. P., Rigoli, D., Martin, N. C., \& Levy, F. (2011). Motor disorder and anxious and depressive symptomatology: a monozygotic co-twin control approach. Research in developmental disabilities, 32(4), 1245-1252.

Piek, J. P., Barrett, N. C., Allen, L. S. R., Jones, A., \& Louise, M. (2005). The relationship between bullying and self-worth in children with movement coordination problems. British Journal of Educational Psychology, 75(3), 453-463.

Piek, J. P., Barrett, N. C., Smith, L. M., Rigoli, D., \& Gasson, N. (2010). Do motor skills in infancy and early childhood predict anxious and depressive symptomatology at school age? Human Movement Science, 29(5), 777-786.

Piek, J., Baynam, G.B. \& Barrett, N.C (2006) The relationship between fine and gross motor ability, self-perceptions and self-worth in children and adolescents. Human Movement Science, 25(1), 65-75. 
Piek, J. P., Rigoli, D., Pearsall-Jones, J. G., Martin, N. C., Hay, D. A., Bennett, K. S., \& Levy, F. (2007). Depressive symptomatology in child and adolescent twins with attention-deficit hyperactivity disorder and/or developmental coordination disorder. Twin Research and Human Genetics, 10(4), 587-596.

Pitrou, I., Shojaei, T., Wazana, A., Gilbert, F., \& Kovess-Masféty, V. (2010). Child overweight, associated psychopathology, and social functioning: a french school-based survey in 6-to 11-year-old children. Obesity, 18(4), 809-817.

Polanczyk, G. V., Salum, G. A., Sugaya, L. S., Caye, A., \& Rohde, L. A. (2015). Annual Research Review: A meta-analysis of the worldwide prevalence of mental disorders in children and adolescents. Journal of Child Psychology and Psychiatry, 56(3), 345-365.

Poulsen, A. A., Ziviani, J. M., Cuskelly, M., \& Smith, R. (2007). Boys with developmental coordination disorder: Loneliness and team sports participation. American Journal of Occupational Therapy, 61(4), 451-462.

Pratt, M. L., \& Hill, E. L. (2011). Anxiety profiles in children with and without developmental coordination disorder. Research in Developmental Disabilities, 32(4), 1253-1259.

Puhl, R. M., Latner, J. D., O'Brien, K., Luedicke, J., Forhan, M., \& Danielsdottir, S. (2016). Cross-national perspectives about weight-based bullying in youth: nature, extent and remedies. Pediatric Obesity, 11(4), 241-250.

Quek, Y. H., Tam, W. W., Zhang, M. W., \& Ho, R. (2017). Exploring the association between childhood and adolescent obesity and depression: a meta-analysis. Obesity Reviews, 18(7), 742-754.

Reillo, M., Vlahov, E., Bohren, J., Leppo, M., \& Davis, D. (2010). Preschool Children's Level of Proficiency in Motor Skills and the Level of their Physical Fitness as Adolescents. Sport Journal, 13(3).

Rigoli, D., Piek, J. P., \& Kane, R. (2012). Motor coordination and psychosocial correlates in a normative adolescent sample. Pediatrics, 129(4), e892-e900.

Roebers, C. M., \& Kauer, M. (2009). Motor and cognitive control in a normative sample of 7year-olds. Developmental Science, 12(1), 175-181.

Schoemaker, M. M., \& Kalverboer, A. F. (1994). Social and Affective Problems of Children Who Are Clumsy: How Early Do They Begin? Adapted Physical Activity Quarterly, 11(2), 130-140.

Schwartz, D., Farver, J., Change, L., \& Lee-Shin, Y. (2002). Victimization in South Korean children's peer groups. Journal of Abnormal Child Psychology, 30(2), 113-125.

Senne, J. A. (2016). Examination of Gender Equity and Female Participation in Sport. The Sport Journal, 19, 1-8.

Sigurdsson, E., Van Os, J., \& Fombonne, E. (2002). Are impaired childhood motor skills a risk factor for adolescent anxiety? Results from the 1958 UK birth cohort and the National Child Development Study. American Journal of Psychiatry, 159(6), 1044-1046.

Skinner, R. A., \& Piek, J. P. (2001). Psychosocial implications of poor motor coordination in children and adolescents. Human Movement Science, 20(1), 73-94. 
Southall, J. E., Okely, A. D., \& Steele, J. R. (2004). Actual and perceived physical competence in overweight and non-overweight children. Pediatric Exercise Science, 16(1), 15-24.

Smyth, M. M., \& Anderson, H. I. (2000). Coping with clumsiness in the school playground: Social and physical play in children with coordination impairments. British Journal of Developmental Psychology, 18(3), 389-413.

Statistics Canada (2016). Table 051-0001 estimates of population, by age group and sex. Canada: provinces and territories, annual (persons). Retrieved from: http://www5.statcan.gc.ca/cansim/a26?id=510001

Vessey, J. A., Duffy, M., O'Sullivan, P. \& Swanson, M. (2003). Assessing teasing in school-age youth. Issues in Comprehensive Pediatric Nursing, 26(1), 1-11.

Tremblay, M. S., Warburton, D. E., Janssen, I., Paterson, D. H., Latimer, A. E., Rhodes, R. E., ... \& Murumets, K. (2011). New Canadian Physical Activity Guidelines. Applied Physiology, Nutrition, and Metabolism, 36(1), 36-46.

Trost, S. G., Sirard, J. R., Dowda, M., Pfeiffer, K. A., \& Pate, R. R. (2003). Physical activity in overweight and non-overweight preschool children. International Journal of Obesity, 27(7), 834-839.

Tseng, M. H., Howe, T. H., Chuang, I. C., \& Hsieh, C. L. (2007). Co-occurrence of problems in activity level, attention, psychosocial adjustment, reading and writing in children with developmental coordination disorder. International Journal of Rehabilitation Research, 30(4), 327-332.

Ulrich, D. A. (2013). The Test of Gross Motor Development-3 (TGMD-3): Administration, Scoring, and International Norms. Hacettepe Journal of Sport Sciences, 24(2), 27-33.

Vannatta, K., Gartstein, M. A., Zeller, M., \& Noll, R. B. (2009). Peer acceptance and social behavior during childhood and adolescence: How important are appearance, athleticism, and academic competence? International Journal of Behavioral Development, 33(4), 303-311.

Vila, G., Zipper, E., Dabbas, M., Bertrand, C., Robert, J. J., Ricour, C., \& Mouren-Siméoni, M. C. (2004). Mental disorders in obese children and adolescents. Psychosomatic Medicine, 66(3), 387-394.

Wassenberg, R., Feron, F. J., Kessels, A. G., Hendriksen, J. G., Kalff, A. C., Kroes, M., ... \& Vles, J. S. (2005). Relation between cognitive and motor performance in 5-to 6-year-old children: Results from a large-scale cross-sectional study. Child Development, 76(5), 1092-1103.

Webster, E. K., \& Ulrich, D. A. (2017). Evaluation of the psychometric properties of the test of gross motor development. Journal of Motor Learning and Development, 5(1), 45-58.

World Health Organization (2010) Global recommendations on physical activity for health. Retrieved from: http://www.who.int/dietphysicalactivity/factsheet_young_people/ 